\title{
Catalytic Converters and PAH Pollution in Urban Areas
}

\author{
Federico Valerio, Anna Stella, Mauro Pala, Daniele Balducci, \\ Maria Teresa Piccardo and Massimo Cipolla \\ National Cancer Research Institute, Environmental Chemistry Service, Genoa, \\ Italy
}

\section{Introduction}

Every organic substance containing carbon and hydrogen yields a large number of polycyclic aromatic hydrocarbons (PAH) during incomplete combustion or pyrolysis or during the formation of petroleum and coal. PAHs are included in a class of chemical compounds characterised by two or more condensed aromatic rings. Several PAHs have been classified by the International Agency for Research on Cancer (IARC) as probable or possible human carcinogens (IARC, 1987).

Due to their carcinogenic and mutagenic effects, sixteen PAHs were included in the US EPA priority pollutant list (Yan, Wang et al., 2004); between them, benzo(a)pyrene (BaP), with five condensed aromatic rings, is recognised as the PAH with the highest carcinogenic potency and is considered to be an indicator of the presence of the PAH group in environmental matrices: air, water, soil, food. In fact in every analysed mixture, the BaP concentration fits linearly with the concentrations of other semi volatile PAHs, prevalently adsorbed to airborne particulate matter.

\section{PAH sources}

Major sources of PAHs include transportation vehicles, coke ovens, steel and iron furnaces, metal smelter, manufactured gas plants, petroleum cracking, coal tar pitch, power generation using fossil and bio fuels, incineration of wastes and domestic heating. Traffic and coal related sources, have been considered to be the two most important source categories in many metropolitan areas in 20th and 21th century (Menichini, 1992; Harrison, Smith et al., 1996).

Even if contribution of motor vehicles to global PAH emissions may be less than biomass burning and wildfire, as estimated in China (Zhang, Tao et al., 2009) and in UK (DEFRA, 2001), traffic emissions occur mostly in urban areas where population densities are much higher than the global average and drivers (Piccardo, Stella et al., 2004), passengers of surface public transport (Kaur, Nieuwenhuijsen et al., 2007) and people working near heavy traffic streets (Piccardo, Stella et al., 2003) may be heavily exposed to traffic pollutants and particularly to PAHs. It was estimated that the most important source of environmental BaP, inhaled by Chinese population, is traffic emission (Zhang, Tao et al., 2009). 
Occurrence of PAHs in vehicle emissions is mainly due to incomplete fuel combustion, which also explains another important traffic pollutant: carbon monoxide (CO) (WHO, 1999). For this reason, contemporary measures of $\mathrm{CO}$ and PAH concentrations along heavy traffic streets are frequently linearly correlated (Valerio, Stella et al., 2000; Lodovici, Venturini et al., 2003).

\section{Trends of PAH concentrations}

Several studies carried out in Europe during the last few decades demonstrated a generalized temporal decrease in the concentration of polycyclic aromatic hydrocarbons (PAH) in air (Fertmann, Tesseraux et al., 2002), in biological samples (Jacob, Grimmer et al., 1997) and in urban areas (Fertmann, Tesseraux et al., 2002; Schauer, Niessner et al., 2003; Menichini, Belladonna et al., 2006). Possible explanations for the short time observed decline of PAH concentrations in European countries were seasonal factors as photo degradation (Schauer, Niessner et al., 2003), different contamination of air masses impacting monitored sites, specific local emissions, i.e. domestic heating (Prevedouros, Brorstrom-Lunden et al., 2004) and industrial activities (Fertmann, Tesseraux et al., 2002). Regulations designed to reduce emissions from mobile sources were identified as possible explanation for long time PAH pollution trends (Menichini, Belladonna et al., 2006), but no clear demonstration was offered by authors for these hypotheses.

Temporal declines of PAHs were observed also in USA and Canada. A study on PAH concentration in precipitation at rural sites was conducted by Brun and co-workers who measured the concentrations of 14 PAHs at five sites close to the Gulf of St. Lawrence (Brun, Vaidya et al., 2004). Over the period 1980-2001, these authors reported an apparent longterm decreasing trend at one of their sampling sites (Kejimkujik National Park, in Nova Scotia), where PAH concentrations in rain and snow decreased with a half-life of 6.4 years. The PAH decrease was found to be correlated $(\mathrm{P}<0.05)$ with decreasing sulphate ion concentrations in precipitations and this suggested to authors that the implementation of air pollution abatement programs in Canada and the Unites States, switching from coal to cleaner sources of energy and improved technology for emission abatement was, most likely, responsible for the observed decline.

Similar measurements in precipitations collected near the Great Lakes, from 1997 to 2003, observed a long-term decreasing trend for PAHs collected at Chicago (Sun, Backus et al., 2006).

In a site near Lake Michigan, BaP concentrations, measured from 1991 to 1997, decreased with an apparent half-life of 4.9 years (Cortes, Basu et al., 2000).

In New York City, PAH levels ( $\Sigma 8$ PAHs) from personal monitoring of pregnant mothers, collected from 1998 to 2006, showed an important decrease (from $3.3 \mathrm{ng} \mathrm{m}^{-3}$ in 1998 to $0.4 \mathrm{ng}$ $\mathrm{m}^{-3}$ in 2006). After controlling for environmental tobacco smoke, indoor heat and cooking, years of personal monitoring remained a predictor of this decline (Narvaez, Hoepner et al., 2008) but specific explanation of this trend was not found.

\subsection{Half-lives of PAH concentrations in atmosphere}

To better describe the progressive decline of PAH concentrations in the atmosphere, Prevedouros proposed the calculation of apparent half-life, i.e. time (years) expected for the reduction to half of the mean annual PAH concentrations (Prevedouros, Brorstrom-Lunden et al., 2004). 
According to this method, firstly, data are logarithmically transformed to reduce their skewness, a common practice when examining environmental datasets. In such a way the standard deviation/variability in the data was reduced, making it less likely that outliers drive the observed trends. Then, the natural logarithm of daily PAH concentrations $(\mathrm{Y})$ are regressed with the progressive number of days $(X)$ during which the trend was observed.

If a significant linear trend line is obtained, the half-life of this trend $\left(t_{1 / 2}\right)$ may be calculated by the slope $(\mathrm{A})$ of the regression line, applying the following equation:

$$
\mathrm{t}_{1 / 2}=-\log _{\mathrm{n}} 2 / \mathrm{A}
$$

The obtained half-lives allow comparing different long time PAH trends available from studies carried out in different situations. The only condition for a correct comparison is that available data cover a long observation period with constant sampling frequency during each year, to avoid seasonal artefacts.

\section{PAH regulations}

Because of their toxic and persistent properties, in 1998, PAHs were included in the UNECE Convention on Long-Range Transboundary Air Pollution (LRTAP) Protocol on Persistent Organic Pollutants (POP) which entered into force in 2003 (UN-ECE, 1998).

This protocol obliges parties to reduce emissions of PAHs and other persistent compounds, below their levels occurring in 1990.

According to estimated PAH emissions in European countries, the implementation of this protocol induced an important reduction of the quantity of PAHs annually emitted into the atmosphere (Denier van der Gon, van het Bolscher et al., 2007). In the EEA-32 region, estimated emissions of PAHs have fallen by $60 \%$ between 1990 and 2008. A combination of targeted legislation coupled with improved controls and abatement techniques has led to significant progress been made in most European countries to reduce PAH emissions. While the majority of individual countries report PAH emissions which have decreased since 1990, there are eight countries (Denmark, Estonia, Portugal, Latvia, Italy, Iceland, Norway, and Sweden) in which increased PAH emissions have occurred (European_Environment_Agency, 2010). In particular, total PAHs estimated to be emitted in Italy, during 2008, were 156.2 tons; their main sources (40\%) were domestic heating plants. During the same year, Italian passenger vehicles emitted 1.67 tons of PAHs (1\%) (SINANET, 2009).

The $\mathrm{BaP}$ indicator approach was used for regulatory purposes in the PAH risk assessment, and gave rise to air quality objectives for BaP in several countries: in Italy, since 1999, the $\mathrm{BaP}$ air quality was set at $1 \mathrm{ng} \mathrm{m}^{-3}$ (Menichini, 1992); the same target value $\left(1 \mathrm{ng} \mathrm{m}^{-3}\right)$ was introduced in the European Community's fourth Air Quality Daughter Directive (2005/107/EC), while in UK, the proposed air quality standard for $\mathrm{BaP}$ is $0.25 \mathrm{ng} \mathrm{m}^{-3}$, as annual mean concentration (DEFRA, 2001).

\subsection{European Regulations to reduce vehicle emissions}

In 1993, all European Union countries adopted Directive 91/441/CEE 06/26/1991, which introduced acceptable limits for exhaust emissions of new vehicles sold in EU member states, and defined the first set, referred to as Euro 1, of acceptable emission limits. Increasingly stringent standards for the regulation of air pollutants $(\mathrm{CO}$, hydrocarbons, 
nitrogen oxide, particulates) were introduced in 1996 (Euro 2), in 2000 (Euro 3), in 2005 (Euro 4) and in 2008 (Euro 5). Accordingly, since 1993, catalytic converters have been obligatory on new gasoline vehicles sold in European countries, and new diesel motors and motorcycle engines have been improved progressively to reduce their emissions.

In 1994, the Italian Health and Environment Ministries established technical regulations to monitor BaP in Italian towns with more than 150,000 residents. To reduce high pollutant levels found in Italian urban areas, in 1997, the Italian Environment Ministry passed a decree containing economic incentives favouring replacement of old cars (EURO 0) with less polluting cars.

To reduce air pollution in urban areas, local measures to limit the number of circulating vehicles were also taken, such as payment of a ticket for cars entering the city (Beevers and Carslaw, 2005) or restriction of the passage of EURO 0 cars, during rush hours.

PAHs are classified as unregulated automobile exhaust constituents, which means that no legal limit exists for their concentrations in vehicle emissions. Thus, less information is available on the effects of catalyst systems on reducing $\mathrm{PAH}$ and $\mathrm{BaP}$ concentrations in vehicle emissions. A thorough review on PAH emission factors for motor vehicles was conducted by Shen (Shen, Tao et al., 2011) who revealed that Emission Factors reported by different laboratories varied more than 4 orders of magnitude, primarily due to the influence of many factors, including country were the test was performed, vehicle model year, vehicle and fuel type, operation mode, ambient temperature (Baek, Field et al., 1991). Ambient temperature is a critical variable for amount of pollutants emitted by catalysed vehicles. Catalytic converters must reach high temperatures to significantly reduce the concentration of pollutants emitted and this condition is reached after a few minutes after the ignition time and this time, in turn, depends on air temperature (Weilenmann, Soltic et al., 2005). For example, a three-way catalyst car, run in accordance with the European driving Cycle, at different ambient temperature, emitted, each kilometre run, $0.16 \mu \mathrm{g}$ of $\mathrm{BaP}$ at $22^{\circ} \mathrm{C}, 26 \mu \mathrm{g}$ at $-7^{\circ} \mathrm{C}, 116 \mu \mathrm{g}$ at $-20^{\circ} \mathrm{C}$ (Ludykar, Westerholm et al., 1999).

Notwithstanding these uncertainties, the introduction of catalytic converters decreased $\mathrm{PAH}$ emissions of diesel and gasoline vehicles and Table 1 shows emission factors of $\mathrm{CO}$ (Wikipedia) and BaP (DEFRA, 2001) of European vehicles, according to different EURO classifications.

\begin{tabular}{|c|c|c|c|c|c|}
\hline & & \multicolumn{2}{|c|}{ Diesel cars } & \multicolumn{2}{c|}{ Gasoline cars } \\
\hline & date & CO & BaP & CO & BaP \\
\hline EURO 0 & Pre-1992 & & 2.85 & 13.9 & 2.38 \\
\hline Euro 1 & July 1992 & 2.72 & 0.63 & 2.72 & 0.26 \\
\hline Euro 2 & Jan 1996 & 1.0 & 0.38 & 2.2 & 0.26 \\
\hline Euro 3 & Jan 2000 & 0.64 & & 2.3 & \\
\hline Euro 4 & Jan 2005 & 0.50 & & 1.0 & \\
\hline Euro 5 & Sept 2009 & 0.500 & & 1.000 & \\
\hline
\end{tabular}

Table 1. Emission factors for $\mathrm{CO}(\mathrm{g} / \mathrm{km})$ and $\mathrm{BaP}(\mu \mathrm{g} / \mathrm{km})$ of European vehicles, according to EURO classifications and date of their becoming effective

\section{Trends of BaP daily concentrations in two Italian streets}

Genoa (610,307 residents according to 2001 census) is one of the most important Italian ports of the Mediterranean Sea. In this city, since 1994, the Genoa Province, in collaboration with 
the National Cancer Institute and the Regional Environmental Protection Agency, has implemented a network of six monitoring stations to measure regulated air pollutants and PAHs adsorbed to airborne particulate (Valerio, Pala et al., 1996; Menichini, Belladonna et al., 2006). Two traffic oriented sampling stations (Site A and Site B), placed along two canyon streets, were selected to study long term trends of $\mathrm{BaP}$ concentrations with prevalent origin from vehicular traffic.

Both monitoring sites are within the urban area where limitations on the driving of EURO 0 vehicles have been applied by the Genoa Council, since September 1998.

Site A was located along a three-carriageway street with a total width of $15 \mathrm{~m}$ and a mean building height of about $20 \mathrm{~m}$ along both sides. The mean daily flow was about 27,000 vehicles, mainly passenger cars. This is the only monitoring site in Genoa where the local traffic flow of four wheels auto vehicles was measured automatically, by electromagnetic coils embedded in the asphalt layer, till 2002.

Site B was near a five-carriageway street, with an estimated daily traffic flow of about 35,000 vehicles, with a total width of $21 \mathrm{~m}$ and a mean building height of about $20 \mathrm{~m}$ along both sides. In both sites, sampling started in September 1994 and the last samples evaluated in this study were collected in 2009. Altogether, 292 daily samples from site A and 261 from site B were analysed.

Two different periods were studied separately. The first period, from September 1994 to September 2002, assessed the possible effect of the gradual reduction of EURO 0 cars, which began in Italy in July 1992, replaced by EURO 1 cars (since July 1992), EURO 2 (January 1996) and EURO 3 (January 2000).

The second period evaluated trend of $\mathrm{BaP}$ daily concentrations from October 2002 to September 2009. During this second period, all new cars registered since January 2005 were classified EURO 4 and around 2006, according to our estimates, the majority of EURO 0 cars were no longer in circulation along the streets of Genoa. Details on sampling, analysis and quality control were previously published (Valerio, Stella et al., 2000; Valerio, Stella et al., 2009). In brief, samples of airborne particulate matter $\left(\mathrm{PM}_{10}\right)$ were collected on glass-fibre filters using high-volume samplers. Samples for 24 hours were collected from midnight to midnight. Sampling days were selected randomly and, according to the sampling program, four daily samples per month were collected simultaneously at each site. Occasional sampler failures, other technical problems during analyses and interruptions during important maintenance works along the monitored streets, reduced the planned frequency of samples collection.

The cyclohesane soluble compounds present on the filters were extracted by sonication; the PAHs were separated by SPE technique and analyzed by GLC with a capillary column and flame ionization detector.

\subsection{Results}

At each site, during the first observation period, the slopes of the natural logarithm of daily concentrations of $\mathrm{BaP}$ versus Julian days (progressive day counter from the first sampling day, September 1, 1994 until September 15, 2002) were calculated and results are shown in Figure 1. Apparent half-lives of BaP were evaluated (Prevedouros, Brorstrom-Lunden et al., 2004), dividing each calculated slope by $\ln 2$.

In Figure 1 the typical seasonal BaP trend (Larsen and Baker, 2003; Schauer, Niessner et al., 2003) may be observed, with the higher daily concentrations in winter and the lowest in summer. 

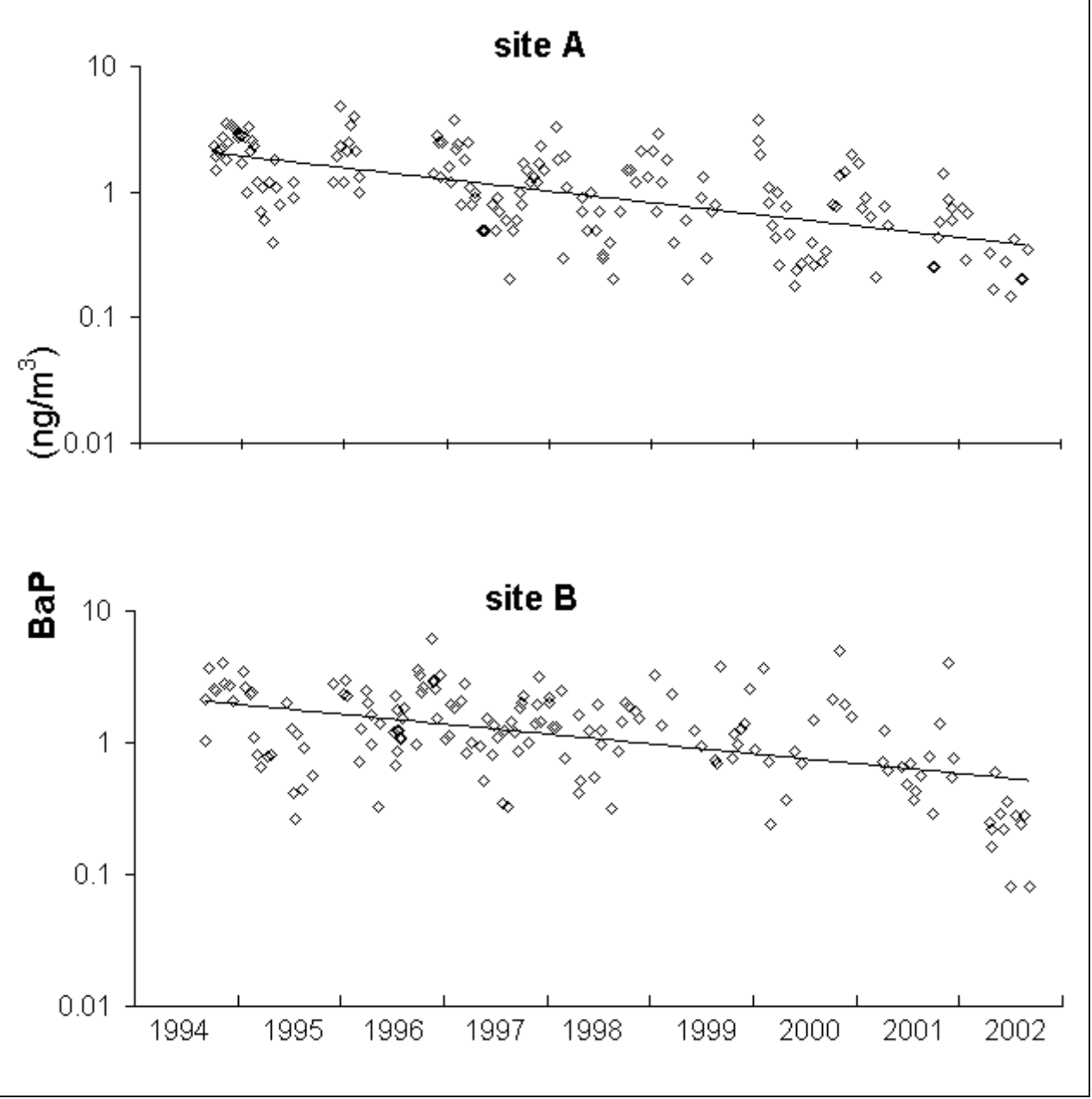

Fig. 1. Temporal trends for $\mathrm{BaP}\left(\mathrm{ng} \mathrm{m}^{-3}\right)$ concentrations at two oriented-traffic sites in Genoa (site A and B) from 1994 to 2002. Logarithmic daily BaP concentrations with regression lines

Figure 1 shows that, in both sampling sites, during the first nine years of monitoring (19942002) there was a constant decrease in the daily BaP concentrations and the calculated regression lines were both statistically significant $(\mathrm{p}<0.0001)$.

Table 2 shows the mean apparent half-lives and confidence intervals (95\%) of BaP at Site A and at Site B found in this study, compared with other half lives found during similar periods in Europe, in United States and Canada.

Mean half-lives for BaP found in the two traffic oriented sites in Genoa are between 3.3 and 4.0 years, respectively, values no statistically different $(\mathrm{p}<0.01)$.

Figure 2 shows the BaP trends during the second period, Oct 2002- Sept 2009.

During the second period, 125 samples were collected in Site A and 99 in Site B. 
The daily $\mathrm{BaP}$ concentrations, during the eight monitored years, showed no statistically significant trend (Figure 2).

Therefore $\mathrm{BaP}$ annual means may be considered constant and their values, in the second period, were $0.39 \mathrm{ng} \mathrm{m}^{-3}(95 \% \mathrm{Cl}=0.08)$ in Site $\mathrm{A}$ and $0.54 \mathrm{ng} \mathrm{m}^{-3}(95 \% \mathrm{Cl}=0.08)$.in Site $\mathrm{B}$, well below Italian air quality standards for $\mathrm{BaP}\left(1.0 \mathrm{ng} / \mathrm{m}^{3}\right.$, daily annual mean).

More precisely, BaP air quality standard was constantly met at Site A, starting from 1998 and at Site B from 2001, till the last available annual samplings, carried out during 2010 in Site A and during 2009, in Site B.
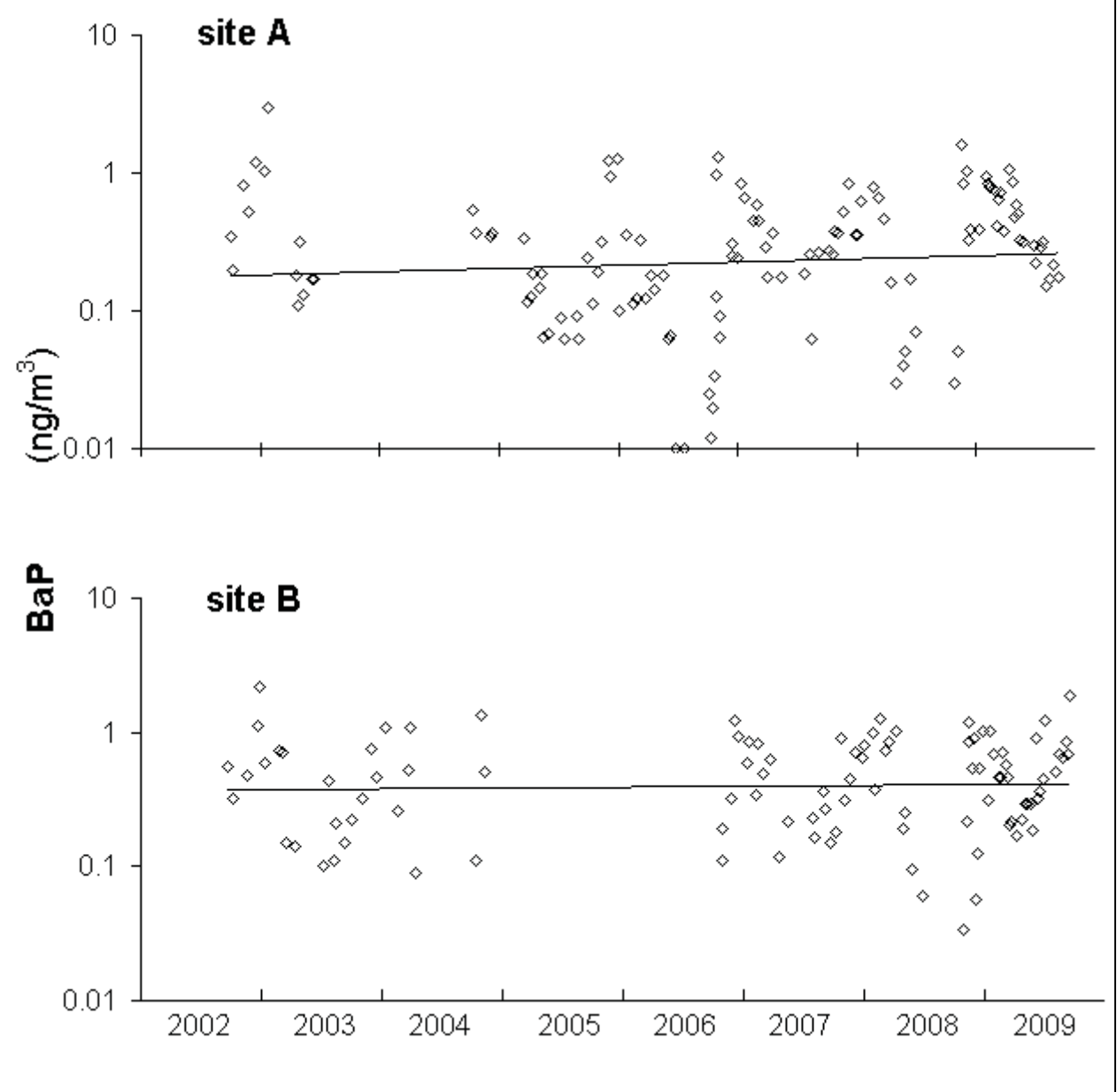

Fig. 2. Temporal trends for $\mathrm{BaP}\left(\mathrm{ng} \mathrm{m}^{-3}\right)$ concentrations at two oriented-traffic sites in Genoa (site A and B) from October 2002 to September 2009. Logarithmic daily BaP concentrations with regression lines 


\begin{tabular}{|c|c|c|c|c|c}
\hline References & Period & site & $\begin{array}{c}\text { half life } \\
\text { year }\end{array}$ & $\begin{array}{c}\text { lower Cl } \\
\text { year }\end{array}$ & $\begin{array}{c}\text { Upper Cl } \\
\text { year }\end{array}$ \\
\hline Cortes,2000 & $1991-1997$ & Lake Michigan & 4.9 & & \\
\hline Sun, 2006 & $1997-2003$ & Chicago & $2.4 \pm 0.6$ & & \\
\hline Meijer, 2008 & $1991-2005$ & London & 4.6 & 3.1 & 7.6 \\
\hline Meijer, 2008 & $1991-2005$ & Manchester & 4.8 & 3.2 & 9.4 \\
\hline Meijer,2008 & $1991-2005$ & Middlesbrough & 7.4 & 5.0 & 14.6 \\
\hline Menichini, 2006 & $1993-2004$ & Rome & 9 & & \\
\hline Menichini, 2006 & $1996-2004$ & Florence & 5 & & \\
\hline Valerio & $1994-2002$ & Genoa A & 3.3 & 2.9 & 3.8 \\
\hline Valerio & $1994-2002$ & Genoa B & 4.0 & 3.2 & 5.4 \\
\hline
\end{tabular}

Table 2. Half lives (years) and lower and upper confidence limits at 95\%, for BaP calculated in this study compared with other long term samplings carried out in USA, Canada, in UK and in Italy.

\subsubsection{Multivariate analyses on BaP concentration}

At site A the daily traffic flow, measured from 1994 to 2002, was constant with a mean value of 26,128 vehicles day-1 (range: 14,360 - 30,946). According to percentage of catalysed vehicles estimated to circulate in Genoa, daily passages of EURO 0 vehicles (NCcars) were calculated; NCcars, daily mean temperature $\left(\mathrm{T} ;{ }^{\circ} \mathrm{C}\right)$, daily ozone concentration $\left(\mathrm{O}_{3} ; \mu \mathrm{g} \mathrm{m}^{-3}\right)$ and relative humidity $(\mathrm{RH} ; \%)$ were tested in a multivariate analyses as possible variables of daily $\mathrm{BaP}$ and $\mathrm{CO}$ concentrations, measured in site $\mathrm{A}$.

Significant multiple regression equations found in this study (Valerio, Stella et al., 2009) are the followings:

$$
\begin{gathered}
\ln [\mathrm{CO}]=0.85-0.005\left[\mathrm{O}_{3}\right]+5210^{-6} \text { NCcars } \quad \mathrm{R}^{2}=0.62 \\
\ln [\mathrm{BaP}]=-0.07-0.013\left[\mathrm{O}^{3}\right]-0.007 \mathrm{RH}+10110^{-6} \text { NCcars } \quad \mathrm{R}^{2}=0.67
\end{gathered}
$$

Both $\mathrm{CO}$ and $\mathrm{BaP}$ mean daily concentrations correlated positively with the estimated number of EURO 0 vehicles passing along this street, during the sampling. The high standardised $\beta$ coefficients for NCcars variable ( 0.57 for $\mathrm{CO}$ and 0.51 for $\mathrm{BaP}$ ) confirm the relevance of EURO 0 vehicle emissions in air pollution measured along this canyon street.

Daily $\mathrm{BaP}$ concentration was negatively correlated with $\mathrm{O}_{3}$ concentration and relative humidity, confirming similar previous studies (Valerio and Pala, 1991; Valerio, Stella et al., 2000; Prevedouros, Brorstrom-Lunden et al., 2004).

The only ambient variable found significant for $\mathrm{CO}$ concentrations measured in Site A was the $\mathrm{O}_{3}$ concentration

According to the mean annual substitution of EURO 0 vehicles, estimated to occur in Genoa in 2006, no EURO 0 cars were in use in this town. 
The $\mathrm{BaP}$ and $\mathrm{CO}$ concentrations, regressed using equations 2) and 3), for zero EURO 0 transits (NCcars $=0$ ) and using mean annual temperature, humidity and ozone concentrations measured in Genoa in 2006, are $0.2 \mathrm{ng} \mathrm{m}^{-3}$ and $1.7 \mathrm{mg} \mathrm{m}^{-3}$, respectively .

These values are comparable to $\mathrm{BaP}$ and $\mathrm{CO}$ annual means, actually measured at site $\mathrm{A}$ in 2006 (BaP: $0.18 \pm 0.06 \mathrm{ng} \mathrm{m}^{-3}, \mathrm{~N}=27 ; \mathrm{CO}: 0.9 \pm 0.7 \mathrm{mg} \mathrm{m}^{-3}$ ).

\subsection{Discussion on BaP trends found in Genoa}

Traffic is certainly the main source of $\mathrm{BaP}$ measured in the two Genoa streets. All results agree with this statement.

Indeno (cd) pyrene and benzo (ghi) perylene are two PAHs analysed for this study. Their mean ratio, in 553 samples collected during the whole sampling period (1994-2009), was $0.44 \pm 0.08$, in agreement with values found in emissions of gasoline vehicles (Caricchia, Chiavarini et al., 1999) and gasoline is the fuel that in 1994 was prevalently used by 293.514 motor vehicles circulating in Genoa. In the same year, light duty diesel cars were about the 7 $\%$ of used motor vehicles and their number increased progressively ( $30 \%$ in 2008). Also circulating motor vehicles increased during the studied period: 66,000 in 1994, 112,000 in 2003 , and 132,148 in 2008. However, diesel cars and motorcycles prevalently substituted gasoline cars as the total numbers of vehicles circulating in Genoa changed from 382,565 in 1994 to 412,456 in 2008.

Multivariate analysis carried out in this study (equations 2 and 3) estimated the role of EURO 0 cars on air pollution and confirmed that the predominant source of $\mathrm{BaP}$ found along the two streets of Genoa was the number of EURO 0 vehicles passing along these streets.

Therefore, the progressive substitution of EURO 0 vehicles with EURO 1, EURO 2 and EURO 3, is the main explanation of the important reduction of mean BaP concentrations occurred between 1994 and 2002: 86\% in site A and 89\% in site B.

The importance of replacing EURO 0 vehicles to reduce air pollution in urban areas, was confirmed by the constant low BAP concentrations in the entire second period (Figure 2), during which only a small percentage of Euro 0 vehicle was estimated to be still in circulation. Statistics on the age of vehicles used in Genoa were available only since 2008 (ACI, 2009); during this year, the EURO 0 cars circulating in Genoa were only $10 \%$ of the total vehicles fleet (gasoline and diesel powered cars and motorcycles).

The BaP decrease found in the atmosphere in two streets in Genoa from 1994 to 2002

(Figure 1) was similar to that found in other European towns during the same period.

In a suburban sampling location in Munich, the air mass concentration of PAHs with 3 to 6 aromatic rings was $8 \mathrm{ng} \mathrm{m}^{-3}$ in 1991 and $2 \mathrm{ng} \mathrm{m}^{-3}$ in 2001/02. The decrease was $76-94 \%$ for the 3 and 4 ring PAHs and 92-96\% for 5 and 6 ring PAHs. In particular, the abundance of $\mathrm{BaP}$ was reduced by $95 \%$.

A significant decrease of $\mathrm{BaP}$ was observed in air samples collected in the North Rhine Westphalia area: the median concentration was $1.6 \mathrm{ng} \mathrm{m}^{-3}$ in 1991 and $0.7 \mathrm{ngm}^{-3}$ in 1997 (Fertmann, Tesseraux et al., 2002)

Airborne PAHs, monitored regularly at rooftop height from 1991 to 1998 in London and Manchester (UK), exhibited a clear decreasing trend at both sites: 4.1 years was the half-life calculated for BaP (Prevedouros, Brorstrom-Lunden et al., 2004).

More recently, another study updated to 2005 the PAH concentrations found in six UK locations (Meijer, Sweetman et al., 2008). Particularly, in the three urban sites (London, Manchester and Middlesbrough) BaP concentrations, from 1991 to 2005, decreased 
dramatically and since 2001, in these three urban sites, the $\mathrm{BaP}$ air quality standard proposed by UK $\left(0.25 \mathrm{ng} \mathrm{m}^{-3}\right)$ exceeded only in winter samples. BaP half-lives, calculated in UK towns are shown in Table 2.

Concentrations of $\mathrm{BaP}$ measured near traffic-oriented sites in nine Italian towns between 1993 and 2004 (Menichini, Belladonna et al., 2006) showed a generalized decreasing trend in the last few years. In six of these towns (Florence, Genoa, Padua, Trieste, Bolzano, Bologna, Rome, and Verona) concentrations of $\mathrm{BaP}$ roughly halved as compared to initial concentrations. In 2004, in seven of these towns, $\mathrm{BaP}$ annual mean values ranged from $0.5 \mathrm{ng}$ $\mathrm{m}^{-3}$ to $1.0 \mathrm{ng} \mathrm{m}^{-3}$. BaP concentrations measured in Florence (1996-2004) and Rome (1993 .2004) near traffic oriented sites (Menichini, Belladonna et al., 2006) decreased with half lives of 5 and 9 years, respectively.

In European towns (Table 2) the longest half-life (9 years) was found in Rome and the lowest (3.3 years) in the site A of Genoa. To explain these differences it is necessary to have information about any change in the number of circulating cars, occurred during the studied period. Indeed, it is possible that a sharp increase of circulating cars may neutralize the lower emissions of new catalyzed vehicles. Therefore, according to the experience shown in Genoa, it is important to monitor traffic intensity near traffic oriented sampling stations.

The decrease of $\mathrm{BaP}$ found in Genoa and in other European towns may share a common explanation: the European Decree that gave to all EU countries, the mandatory requirements for all new gasoline and diesel vehicles sold from 1/1/1993, to respect stringent emission limits. In all European countries, this law caused a progressive substitution of non-catalyser gasoline vehicles with new, less polluting cars and the relevant contribution of traffic emissions to PAH pollution found in European urban areas in the last two decades was confirmed by several studies carried out in Italy (Valerio, Brescianini et al., 1992), the United Kingdom (Harrison, Smith et al., 1996) and Denmark (Nielsen, Jorgensen et al., 1996).

In this case, according to Emission Factors in Table 1, the substitution of EURO 0 vehicles with EURO 1 vehicles may reduce BaP emissions of gasoline cars by $89 \%$ and of diesel cars by $78 \%$.

When, in 1996, all new vehicles sold in European countries were complying with EURO 2 emissions, based on emission factors provided in Table 1, the purchase of a new diesel car, replacing a EURO 0 diesel car, should have further reduced $\mathrm{BaP}$ emissions.

For the following years, emission factors for $\mathrm{BaP}$ in EURO 3, 4, 5 cars are not available. Therefore predictions are not possible. However, according to the aforementioned correlation between the concentrations of $\mathrm{CO}$ and $\mathrm{BaP}$, since 2005, further significant reductions of $\mathrm{CO}$ and probably of $\mathrm{BaP}$ would not have been expected.

\section{Conclusions}

Before this study, it was not taken for granted the drastic air pollution reductions occurred in Genoa could be linked to vehicles fleet renewal. The effectiveness of catalytic converters in urban courses was doubtful (Pornet, Beaubestre et al., 1995) due to the prevalent cold starts and frequent traffic congestions occurring in urban areas.

Notwithstanding mean daily course of only $14 \mathrm{kms}$, it is possible that, in Genoa, the rapid reaching of optimal motor temperatures may have been helped by the mild Mediterranean winters when daily temperatures rarely fall below $0^{\circ} \mathrm{C}$. 
$\mathrm{BaP}$ half-lives found in London and Manchester suggest that catalytic converters and new diesel motors can be effective to reduce air pollution also in climatic conditions of these towns.

The European experience confirms that, in urban areas, the stringent air quality standards proposed for $\mathrm{BaP}$ and related PAHs may be respected.

\section{Acknowledgements}

The authors are indebted to the Genoa Province Administration, the Air Quality Department and, in particular, to Dr E. Daminelli for the financial and technical support that made this study possible.

We thank the Statistic Office of Genoa municipality and Liguria Region, Economic Development Department for their useful collaboration and doctor Marcello Ceppi for his support to statistical analysis of our data.

\section{References}

ACI, (2009).Analisi dell'anzianità del parco veicoli in alcuni comuni capoluogo di provincia, Available from

http://www.aci.it/fileadmin/documenti/studi_e_ricerche/dati_statistiche/Anzia nita/Capitolo_4.pdf

Baek, S.O., R.A. Field, M.E. Goldstone, P.W. Kirk, J.N. Lester R. Perry (1991). A review of atmosheric polycyclic aromatic hydrocarbons: sources, fate and behavior. Water Air and Soil Pollution, Vol. 60,No. 3-4, pp. 279-300.

Beevers, S.D. D.C. Carslaw (2005). The impact of congestion charging on vehicle emissions in London. Atmospheric Environment, Vol.39, No. 1, pp. 1-5.

Brun, G.L., O.C. Vaidya M.G. Leger (2004). Atmospheric deposition of polycyclic aromatic hydrocarbons to Atlantic Canada: geographic and temporal distributions and trends 1980-2001. Environ Sci Technol, Vol. 38,No. 7, pp. 1941-1948.

Caricchia, A.M., S. Chiavarini M. Pezza (1999). Polycyclic aromatic hydrocarbons in the urban atmospheric particulate matter in the city of Naples (Italy). Atmos Environ, Vol.3 3, pp. 3731-3738.

Cortes, D.R., I. Basu, C.D. Sweet R.A. Hites (2000). Temporal Trends in and Influence of Wind on PAH Concentrations Measured near the Great Lakes. Environmental science E technology, Vol. 34, pp. 356-360.

DEFRA, (2001).Assessment of benzo(a)pyrene atmospheric concentrations in the UK to support the establishment of a national PAH objective, Available from http://ukair.defra.gov.uk/reports/empire/aeat-env-r-0620.pdf

Denier van der Gon, H., M. van het Bolscher, A. Visschedijk P. Zandveld (2007). Emissions of persistent organic pollutants and eight candidate POPs from UNECEEurope in 2000, 2010 and 2020 and the emission reduction resulting from the implementation of the UNECE POP protocol. Atmospheric Environment, Vol. 41, No. 40, pp. 92459261.

European_Environment_Agency, (2010).Persistent organic pollutants (POP) emissions (APE 006), Available from http:/ / www.eea.europa.eu/data-andmaps/indicators/eea32-persistent-organic-pollutant-pop-emissions-1 
Fertmann, R., I. Tesseraux, M. Schumann H. Neus (2002). Evaluation of ambient air concentrations of polycyclic aromatic hydrocarbons in Germany from 1990 to 1998. J Expo Anal Environ Epidemiol, Vol. 12,No. 2, pp. 115-123.

Harrison, R.M., D.J.T. Smith L. Luhana (1996). Source apportionment of atmospheric polycyclic aromatic hydrocarbons collected from an urban location in Birmingham, U.K. Environ Sci Technol, Vol. 30,No., pp. 825-832.

IARC (1987). Monographs on the evaluation of the carcinogenic risk of chemicals to humans. Supplement 7. Lyon, France.

Jacob, J., G. Grimmer A. Hildebrandt (1997). Long-term decline of atmospheric and marine pollution by polycyclic aromatic hydrocarbons (PAHS) in Germany. Chemosphere, Vol. 33, No. 9-10, pp. 2099-2108.

Kaur, S., M.J. Nieuwenhuijsen R.N. Colvile, (2007). Fine particulate matter and carbon monoxide exposure concentrations in urban street transport microenvironments, Available from

http://www.sciencedirect.com/science?_ob=GatewayURL\&_origin=ScienceSearch \&_method=citationSearch\&_piikey=S1352231007001343\&_version=1\&_returnURL

$=$ http $\% 3 \mathrm{~A} \% 2 \mathrm{~F} \% 2 \mathrm{Fwww}$. scirus.com $\% 2 \mathrm{Fsrsapp} \% 2 \mathrm{~F} \& \mathrm{md} 5=4 \mathrm{f} 2 \mathrm{a} 07 \mathrm{~d} 19537 \mathrm{f} 6 \mathrm{~d} 08 \mathrm{f} 3 \mathrm{f} 1 \mathrm{c0}$ 0b5a61ca9

Larsen, R.K., 3rd J.E. Baker (2003). Source apportionment of polycyclic aromatic hydrocarbons in the urban atmosphere: a comparison of three methods. Environ Sci Technol, Vol. 37,No. 9, pp. 1873-1881.

Lodovici, M., M. Venturini, E. Marini, D. Grechi P. Dolara (2003). Polycyclic aromatic hydrocarbons air levels in Florence, Italy, and their correlation with other air pollutants. Chemosphere, Vol. 50, No. 3, pp. 377-382.

Ludykar, D., R. Westerholm J. Almen (1999). Cold start emissions at $+22,-7$ and $-20^{\circ} \mathrm{C}$ ambient temperatures from a three-way catalyst (TWC) car: regulated and unregulated exhaust components. The Science of The Total Environment, Vol. 235, No. 1, pp. 65-69.

Meijer, S.N., A.J. Sweetman, C.J. Halsall K.C. Jones (2008). Temporal trends of polycyclic aromatic hydrocarbons in the U.K. atmosphere: 1991-2005. Environ Sci Technol, Vol. 42, No. 9, pp. 3213-3218.

Menichini, E. (1992). Opinion adopted by the Italian National Advisory Toxicological Committee on polycyclic aromatic hydrocarbons. Rome.

Menichini, E. (1992). Urban air pollution by polycyclic aromatic hydrocarbons: levels and sources of variability. Sci Total Environ, Vol. 116, No. 1-2, pp. 109-135.

Menichini, E., V. Belladonna, F. Bergoglio, C. Gabrieli, M. Ceccanti, I. Rossi, L. Cellini, E. Corradetti, D. Grechi, V. Tricarico, M. Rosa, C. Zemello, A. Spiazzi, A. Stella, F. Valerio G.R. Trevisani (2006). Trend of atmospheric benzo(a)pyrene in Italy before the adoption of the European directive on PAHs. Polycyclic Aromatic Compound, Vol. 26, pp. 79-92.

Narvaez, R.F., L. Hoepner, S.N. Chillrud, B. Yan, R. Garfinkel, R. Whyatt, D. Camann, F.P. Perera, P.L. Kinney R.L. Miller (2008). Spatial and temporal trends of polycyclic aromatic hydrocarbons and other traffic-related airborne pollutants in New York City. Environ Sci Tech Vol 42 No 19 pp 7330-7335 
Nielsen, T., H.E. Jorgensen, J.C. Larsen M. Poulsen (1996). City air pollution of polycyclic aromatic hydrocarbons and other mutagens: occurrence, sources and health effects. Sci Total Environ, Vol. 30, No. 20, pp. 41-49.

Piccardo, M.T., A. Stella, A. Redaelli, D. Balducci, R. Coradeghini, C. Minoia F. Valerio (2004). Personal daily exposures to benzo(a)pyrene of taxi drivers in Genoa, Italy. Sci Total Environ, Vol. 330, No. 1-3, pp. 39-45.

Piccardo, M.T., A. Stella, A. Redaelli, C. Minoia F. Valerio (2003). Newsagents' daily personal exposures to benzo(a)pyrene in Genoa, Italy. Atmospheric Environment, Vol. 37, No. 5, pp. 603-613.

Pornet, P., C. Beaubestre, Y. Courtois, H. Ing, B. Lopez J.L. Marduel (1995). Impact des conditions de conduite sur l'efficacite des pots catalytiques de vehicules a essence et diesel. Sci Total Environ, Vol. 169, pp. 321-329.

Prevedouros, K., E. Brorstrom-Lunden, J.H. C, K.C. Jones, R.G. Lee A.J. Sweetman (2004). Seasonal and long-term trends in atmospheric PAH concentrations: evidence and implications. Environ Pollut, Vol. 128, No. 1-2, pp. 17-27.

Schauer, C., R. Niessner U. Poschl (2003). Polycyclic aromatic hydrocarbons in urban air particulate matter: decadal and seasonal trends, chemical degradation, and sampling artifacts. Environ Sci Technol, Vol. 37, No. 13, pp. 2861-2868.

Shen, H., S. Tao, R. Wang, B. Wang, G. Shen, W. Li, S. Su, Y. Huang, X. Wang, W. Liu, B. Li K. Sun (2011). Global time trends in PAH emissions from motor vehicles. Atmospheric Environment, Vol. 45, No. 12, pp. 2067-2073.

SINANET, (2009).Emissioni nazionali di idrocarburi policiclici aromatici (IPA) (PAH) in Italia per l'anno 2008, Available from http://www.sinanet.isprambiente.it/it/sinanet/sstoriche/visualizza

Sun, P., S. Backus, P. Blanchard R.A. Hites (2006). Annual variation of polycyclic aromatic hydrocarbon concentrations in precipitation collected near the Great Lakes. Environ Sci Technol Vol 40 Nº 3 pp. 696-701

UN-ECE, (1998).UN/ECE Convention on Long Range Transboundary Air Pollution. Protocol on Persistent Organic Pollutants, Available from http://www.unece.org/env/lrtap/welcome.html

Valerio, F., C. Brescianini, M. Pala, A. Lazzarotto, D. Balducci V. Fontana (1992). Sources and atmospheric concentrations of polycyclic aromatic hydrocarbons and heavy metals in two Italian towns ( Genoa and La Spezia). Sci Total Environ, Vol. 114, pp. 47-57.

Valerio, F. M. Pala (1991). Effects of temperature on the concentration of polycyclic aromatic hydrocarbons (PAHs) adsorbed onto airborne particulates. Fresenius J Anal Chem, Vol. 339, pp. 777-779.

Valerio, F., M. Pala, A. Lazzarotto, A. Stella, F. Ciccarelli D. Balducci (1996). Air quality standard for benzo(a)pyrene in Genoa (1994-1995). Polycyclic Aromatic Compound, Vol. 9, pp. 61-66.

Valerio, F., A. Stella A. Munizzi (2000). Correlations between PAHs and CO, NO, NO2, O3, along an urban street. Polycyclic Aromatic Compounds, Vol. 20, No., pp. 235-244.

Valerio, F., A. Stella, M. Pala, D. Balducci, M.T. Piccardo M. Cipolla (2009). The effect of euro-0 vehicle substitution on polycyclic aromatic hydrocarbon and carbon monoxide concentrations in an urban area. Atmospheric Environment, Vol. 43, pp. $1520-1526$. 
Weilenmann, M., P. Soltic, C. Saxer, A.-M. Forss N. Heeb (2005). Regulated and nonregulated diesel and gasoline cold start emissions at different temperatures. Atmospheric Environment, Vol. 39, No. 13, pp. 2433-2441.

WHO (1999). Carbon monoxide. Environmental Health criteria. Geneva, Worl Health Organization.

Wikipedia, Available from

http://en.wikipedia.org/wiki/European_emission_standards\#Emission_standard s_for_passenger_cars

Yan, J., L. Wang, P.P. Fu H. Yu (2004). Photomutagenicity of 16 polycyclic aromatic hydrocarbons from the US EPA priority pollutant list. Mutation Research/Genetic Toxicology and Environmental Mutagenesis, Vol. 557, No. 1, pp. 99-108.

Zhang, Y., S. Tao, H. Shen J. Ma (2009). Inhalation exposure to ambient polycyclic aromatic hydrocarbons and lung cancer risk of Chinese population. Proceedings of the National Academy of Science of the United States of America, Vol. 106, No. 50, pp. 21063-21067. 


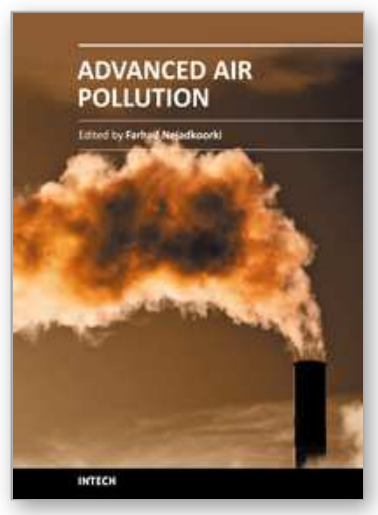

\author{
Advanced Air Pollution \\ Edited by Dr. Farhad Nejadkoorki
}

ISBN 978-953-307-511-2

Hard cover, 584 pages

Publisher InTech

Published online 17, August, 2011

Published in print edition August, 2011

Leading air quality professionals describe different aspects of air pollution. The book presents information on four broad areas of interest in the air pollution field; the air pollution monitoring; air quality modeling; the GIS techniques to manage air quality; the new approaches to manage air quality. This book fulfills the need on the latest concepts of air pollution science and provides comprehensive information on all relevant components relating to air pollution issues in urban areas and industries. The book is suitable for a variety of scientists who wish to follow application of the theory in practice in air pollution. Known for its broad case studies, the book emphasizes an insightful of the connection between sources and control of air pollution, rather than being a simple manual on the subject.

\title{
How to reference
}

In order to correctly reference this scholarly work, feel free to copy and paste the following:

Federico Valerio, Anna Stella, Mauro Pala, Daniele Balducci, Maria Teresa Piccardo and Massimo Cipolla (2011). Catalytic Converters and PAH Pollution in Urban Areas, Advanced Air Pollution, Dr. Farhad Nejadkoorki (Ed.), ISBN: 978-953-307-511-2, InTech, Available from:

http://www.intechopen.com/books/advanced-air-pollution/catalytic-converters-and-pah-pollution-in-urban-areas

\section{INTECH}

open science | open minds

\section{InTech Europe}

University Campus STeP Ri

Slavka Krautzeka 83/A

51000 Rijeka, Croatia

Phone: +385 (51) 770447

Fax: +385 (51) 686166

www.intechopen.com

\section{InTech China}

Unit 405, Office Block, Hotel Equatorial Shanghai

No.65, Yan An Road (West), Shanghai, 200040, China 中国上海市延安西路65号上海国际贵都大饭店办公楼 405 单元

Phone: +86-21-62489820

Fax: $+86-21-62489821$ 
(C) 2011 The Author(s). Licensee IntechOpen. This chapter is distributed under the terms of the Creative Commons Attribution-NonCommercialShareAlike-3.0 License, which permits use, distribution and reproduction for non-commercial purposes, provided the original is properly cited and derivative works building on this content are distributed under the same license. 